\title{
The Exchange-Marriage System, Traditional Gender Roles And Obscured Transformations In A Community Of Pakistan: The Interplay Between Structure, Agency And Social Change
}

\author{
Muhammad Zaman \\ Department of Sociology \\ Qauid-i-Azam University Islamabad
}

Muhammad Zakria Zakar

Director Institute of Social and Cultural Studies

University of Punjab

\author{
Abida Sharif \\ University of Versailles
}

\begin{abstract}
This article deals with the traditional and changing gender roles and relationships in the exchange-marriage system that exists in south Punjab, Pakistan. It examines the structural roles and an individual's independent choices. In-depth interviews were conducted with twenty-four families who have utilized the system of exchange. In this research the guidelines of the Grounded Theory Method (GTM) in order to collect and analyse the data. The study found that pre-determined, structured roles were more influential and they retain more importance than the individual's choices. It revealed a perpetual tension between structural forces and an individual agency: an emancipated individual tries to assert and wants to exercise her/his choice but finds that the structural pressures are powerful. Some contention grows between the structural agents and the individual agency for the freeing of the individual's emancipated role. This paper analyses the interplay between the structure and the agency. It also analyses the tensions and the process of slight social change that occurs under given social conditions.
\end{abstract}

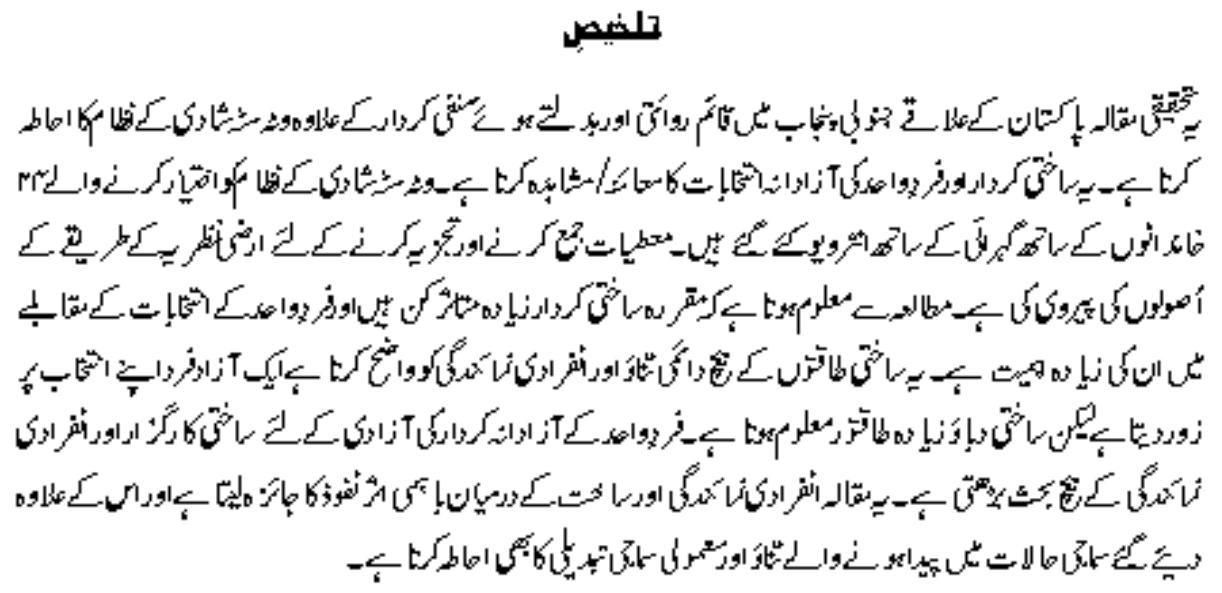



Community of Pakistan: The Interplay between Structure, Agency and Social Change

Key Words: Exchange Marriage, Traditional Gender Role, Agency, Social Change

\section{Background of the Study}

The exchange-marriage system, i.e. reciprocity of a sister/daughter for the marriage of a son/brother, has been long in existence. It is perceived as a system of social welfare, wellbeing and kinship-alliance formation with the objective of protecting the socio-political interests of the families involved in the exchange. There are various studies that have directly dealt with the system of marriage by exchange. Malinowski (1922), Meek (1936), Mass (1954), Levi-Strauss (1969), McDougal (1979), Richard Tapper (1989), Nancy Tapper (1991), Barman (1997), Boride (1998), Schweitzer and White and Heady (2001, 2003) have all investigated the marriage-exchange system from the structural and individualistic perspectives in various parts of the world. However, none of the studies dealt with the traditional gender roles and changing patterns of the exchange-marriage system in Pakistan. This study bridges the gap in the literature on the subject. Differing from previous studies, this study analyses the gender roles and the transformation in the marriage-exchange system in light of the interplay between structure and agency.

Gender relations vary from one society to another. Mass (1954) argued that a woman is perceived as a commodity and is exchanged as a gift between the two families to create social bonding. From his point of view, the system of exchange forms social cohesion. Levi-Strauss (1969) dealt with the exchange marriage as an instrument to develop alliance between families and groups. He viewed marriage by the exchange system and exchanged couples as a strategy to develop alliances. Similarly, Struthers (1984) examined the marriage by exchange in Melanesian. She traced a woman's independent role from the structuralist's perspective in the system of the exchange. She discusses the woman's reproductive role in the labour market that makes her to be considered as a commodity and to be exchanged. In short, women are treated and traded as commodities to be exchanged. However, the exchange's rules and the principals of this commodity vary from one society to another.

Various studies in developing countries have shed light on the strict gender roles assigned to women (Tapper 1997; White and Schweitzer 1998; Zhang 2000). For instance, in Afghanistan, women are forced to perform traditional gender roles by applying the repressive force of gender-related norms. Women are considered to be a family resource and proper control of their behaviour protects the family's honour in the Afghan society. If the control is loosened, it brings enormous shame and humiliation for the family, especially for the dominant man (Tapper, 1991). Kinship politics is an important aspect that brings honour and shame for a person on the one hand. Nancy Tapper (1991) discusses the kinship social structure and power politics based on the resources on the other. She revealed that the exchange system promotes a man's interests whereas a 
woman has to show her loyalty to the man (1991:221). However, findings of the study done by White and Schweitzer (1998) on a community in Java (Indonesia) are contradictory to hers where the marriage is arranged within the matri-lineage only. Local taboos resist arranging a marriage within the matri-lineage. Maternal relationships are stronger than the paternal ones in Java. A woman's position seems to be stronger than that of a man. The sense that exchange marriages are in a man's interests seems to be fuzzy and the gender roles do not correspond with the exchange system that is carried out in Indonesian society.

Culturally, exchange marriages are projected as 'pro-women' and as a functional necessity to safeguard the interests of women. Though, in some cultures, such marriages are resisted, they are also accepted by the girls under the influence and logic presented by the dominant culture. For instance, Zhang (2000: 60) noted that daughters in rural China were not always willing to get married according to the choice of the parents on the basis of exchange. Zhang, however, does not outline why the daughters were resisting their parents' decision of the marriage exchange. His study indicates the desire for emancipation of an individual from the structured role. Contrary to Zhang's study, Jacoby and Mansuri (2008) found willingness in women to have an exchange marriage in the Pakistani study. This study found that the interests and welfare of women are best served by the exchange system. They argued that a woman is in an advantageous position in the exchange system because she confronts the patriarchal authority through this system which, otherwise, is not possible. The findings of this study are also contradictory to Tapper's (1991) arguments when she pointed out that a man looks for his vested interests, but Jacoby and Mansuri (2008) claim that a woman is in an advantageous position in the system. In one culture, certain rules are adopted in order to practise the exchange marriage and, in another culture, one can find variations in those associated with the first culture. Nevertheless, none of the above studies took into consideration the gender-based roles and relationships in the system of the exchange marriage. With the passage of time, these gender-based roles have changed slightly due to education and cross-cultural influences that also affect the marriage system. Furthermore, these studies did not take into account the interaction between structure and agency.

This article examines the structured role, relationships and obscure gender roles/relations inherent in the exchange-marriage system in the community of Kabirwala, located in south Punjab, Pakistan. It also discusses the interaction between the structure and agency and defines how social change comes into view in the system of the exchange marriage.

\section{Objectives of the Study}

This study aims to highlight the gender roles and relationships in traditional social set ups and it also investigates the changing patterns of the role and relationship between the 
youth and their elders. The research also focuses on the role of education in the process of the change. Nonetheless, this change is very obscured. At the theoretical level, it is about the perpetual and simmering tension between the structure and the agency in implementing/resisting the normative regime of spouse selection through the process of the exchange-marriage system.

\section{Method}

The findings of this study are based on field work that was conducted between 2006 and 2007 to explore the issue of exchange marriage. The field work was conducted in the small village of $\mathrm{Murad}^{l}$ in the town of Kabirwala, District Khanewal, south Punjab, Pakistan. Documented proof was found in the District Census Report, Khanewal (2000) which claims that the town operates under a system of exchange marriage. Therefore, this locality was selected for the study. Almost 1,500 persons are living in the village of Murad and its annexed settlements. Overall, the national literacy rate of Pakistan is about $56 \%$ (men - 69\% and women - 44\%) according to the Economic Survey of Pakistan (2009:158). However, an exact literacy rate of the village is not available, but one can observe illiteracy in the village. The population depends on the agrarian economy and most of the people are from the working class with a low level of income.

In order to investigate the exchange-marriage system, the Grounded Theory Method's (GTM) guidelines (Strauss, 1987; Neumann, 1997; Glaser, 1992; Glaser and Strauss, 1965; Larossa, 2005; O'Brien, 2005) were used to conduct and analyse the data. The GTM seems to be appropriate while it guides in developing real insight into the social world (Zaman, 2011). The GTM guides that data collection and analysis is a simultaneous process (Corbin \& Strauss, 1990). We interviewed the couples (each spouse individually) who were married by exchange, their parents and their children who were supposed to get married in the near future after securing their formal permission. In this way, we compiled twenty-four family case histories based on forty-eight individual interviews. Four respondents from the group of spouses declined to be interviewed, however, we added two parents and two young persons in the interview. We used an interview guide as a tool for the collection of the data. As per guidelines of the GTM, we identified themes as we were proceeding with the data collection. In other words, themes and concepts were developed from the data. Since the principal investigator was familiar with the social setting and the local language, it was easy to approach the community and retrieve the relevant data, which has been annotated and interpreted here in this article.

\section{Findings and Discussion}

We found the following themes and categories from the theoretical sampling as per the GTM guidelines (Corbin \& Strauss, 1990; Zaman, 2011). 


\section{Spouse Selection and Gender: Structured and Traditional Roles}

As a part of local tradition, a family prefers to marry its son/daughter within a similar genealogical relatedness (the local term is biradari) on the basis of an exchange. A woman herself feels comfortable to get married to a relative ${ }^{2}$. The woman takes the initiative in arranging the marriage of her daughter/sister. Therefore, they prefer endogamy on the basis of the exchange marriage. Akbar ${ }^{3}$, a 57-year old man tells: "In my opinion women are benefited more in the exchange-marriage system than any other because this system provides complete social security to them."

It is perceived that the strong social bond with a sister/daughter maintains the equality of the relationship with the other exchanged couple. It creates reciprocity in social relationships for the prevention of domestic violence for one's own daughter/sister. A strong bond between brothers and sisters compels a person to be tolerant so that the sister/daughter does not face any problem as per the "rule of the game". It creates 'deterrence' which holds the other man to remain conformed to the norm. These relationships make the actors dependent, connected, adjusted, as well as vulnerable, within the social network of the kin. Ultimately, the system of the exchange strengthens traditional gender roles.

\section{Gender Segregation (chadar and char devari): Restraint Roles}

The marriage-exchange system segregates the genders: both families (involved in the exchange) want to protect their honour at home and do not allow their women to mix with strangers. In the local normative and cultural context, women are supposed to stay inside the home to carry out the household responsibilities. Restricting women to the home also serves the purpose of their segregation from the 'stranger-men' in order to ensure the local notion of strict, protective confinement of women within the four walls of the house locally called as "chadar and char devari".

A woman is supposed to have the company of a mehram (a man who has a kinship relation with the woman) from the family while coming outside of her house. The accompanying person can be her father, brother, a boy/ girl from the family and in the case of non-availability, a child (at least) is considered necessary. The conformity of the woman with the local norms gives her a secure feeling, a sense of belonging and confidence. Nonetheless, only those women who respect these norms are considered respectable and conforming.

However, those who violate these norms may run the risk of being labelled as having a 'loose character'. For example, a woman/girl travelling alone, may be considered to be modern and liberal yet raises questions about her character in the village of Kabirwala. 
Such a woman feels insecure and remains open for stalking, bullying and vulnerability while travelling alone.

Saima, a girl who is 21 years of age expresses how she is forced to be a conformist to the norms of chadar and char devari: "I have no choice but to stay at home because if I were to go outside alone, I would be considered responsible for all of what people would do to humiliate me. This applies to me even if I am married outside of my relatives or I am married without exchange". Another respondent Razia, a 28-year old woman, however has a different consideration of such traditional norms: "I think that a woman should stay at home and marry a cousin as it is against our tradition to go outside alone or to get married without exchange. I think this is for her own benefit if she respects this norm and does not give a chance to others to question her character."

Gender segregation is perceived as a structural solution in order to avoid trouble and restrain the roles of the individual. Therefore, a woman marries within her own extended relatives in order to avoid mixing with strangers on the basis of exchange and the restricted role.

\section{The Hierarchy of Relationships: The Authority of Structural Agents}

Gender relations were found to be hierarchical in the village under investigation. A person can find an organizational chart of the relationships within the extended family with a few omissions and additions, but in certain situations, it is difficult to find hard or soft rules regarding the authority and occasionally one can notice the overlapping of the gender relations. However, usually, authority resides in grandparents, parents, brothers/ sisters in hierarchical order (Qadeer, 2006:200). The hierarchy of the roles determines the authority and relationship among kin. For instance, brothers enjoy more authority after parents than that of sisters, but they are also responsible to take care of their sisters. Among brothers, the elder brother has more respect and he enjoys more decision-making authority after their elders. Between sisters, an elder sister enjoys more respect and honour than the younger ones do.

Grandparents and parents are the heads of the family. They enjoy decision-making authority in every family affair. This rule also applies to the selection of one's spouse. The elders of a family make the marriage decisions of their children after having carried out an in-depth analysis of their perspective future spouses. If the future spouses are educated, then the elders regard their choices in a few cases of spouse selection. In many cases, grandparents decide the matter and everybody, even the parents, are reluctant to challenge this decision. These elders justify their decisions by saying that they have enough experience and authority to decide the marriages properly. They believe what they are doing for their children is in their best interests. Over non-compliance, the 
son/daughter could be declared as deviant. The young generation obeys and appreciates the decisions of the parents as Nadia, a 21-year old, woman respondent tells:

"Look! In our system, young people are not considered mature enough to make the decisions of their marriage. It is the grandparents or parents who make the decision and the youth are expected to obey it silently. Any resistance or questioning on the part of the youth is considered as a sign of disobedience. If it happens to be a girl, the resistance may have catastrophic consequences."

The elders of the family assume authority from traditional interpretations. For instance, a father and a mother are wali (guardians) of the children and the children should obey them. This traditional authority of the parents comes from the customary interpretations that empower them to make the decision and to finalize it, without even considering the 'will' of their children.

After having conducted in-depth interviews, it was revealed that the marrying of one's children is a complex issue in the community of Kabirwala and its complexity mounts when it comes to the question: "Who decides the marriages of the children and how?" In many situations, decision-making does not necessarily require the will of the real actors whose marriage is being decided. However, it is mandatory to consider the elders' opinion about who should marry whom and who should be exchanged for this marriage to take place in the community of Kabirwala. One of the interesting aspects of the decision-making process about the marriage of children is the considerable and important role of elder women. Grandparents decide the marriages, parents agree with their decision and proceed to compel the children to do as their elders wish and have decided. Thus, the latter have no right to deny or utter a single word against their decision. Parents view these marriage decisions as sweet memories of their late elders (if they died); some of the young remain ambivalent, while others accept it. Sometimes, these young people take these decisions as a matter of 'ego' and firmly practise traditions while others may secretly disagree or openly show discontent, but they are hardly able to refuse it. If any of the young people declines, the other will gossip about the disobedience. However, a mother or any other close, female relative plays a pivotal role in the decision of the marriage of her son/daughter or relative while negotiating on the basis of her children.

The mother or any elderly woman shows consent, discontent on the behalf of the children or relative to her husband or parents in-law. Sometimes, she/he uses indirect words to indicate her consent/discontent about a decision. Such a person plays the role of an individual agency that directly or indirectly negotiates on the behalf of the individual concerned (future spouses are not allowed to communicate with their parents directly in general, but exceptions are possible). This is a socially accepted way to safeguard a son/daughter's interests with the structural agents (parents or grandparents in this 
situation). Nevertheless, there is a hierarchy in the relationships that is based on the birth order of a person, gender, age and the relation with kin and has some set patterns to communicate or watch one's own interests within the kin relationship.

\section{The Choice of Spouse: The Dependency Syndrome}

Children are dependent upon their parents until the time of their marriages and, in many cases, even after the marriage. Such a situation has given birth to a dependency that the son/daughter has on his/her parents and/or on the grandparents. If the parents are absent, someone else from the close relatives (especially a close, male relative) takes guardianship of the children. This kinship institution operates as a 'safety network' for the son/ daughter. Amin, a 32-year old man explains:

"The family discusses and decides upon the selection of the mate. However, the important decisions are taken by my father, who is the head of the household or else my mother.... I like their decisions. Whatever they do, they (grandparents or parents) do for our welfare. They are a blessing of God.... Being our elders, they are sensible and experienced as compared to our vision and they can decide right or wrong for us in a better way."

A mother is considered to be more close to the children (than the father) in everyday life because of the emotional attachment in this cultural context. A mother delivers lenient orders as compared to the father's hard actions. A father is expected to exhibit stern behaviour so that the youngster should learn and face the hard realities of life. Nevertheless, the orders of the parents and elders are obligatory to be obeyed. Owing to established, customary practices, children never try to violate such orders.

Saban, a 35-year old woman elaborated her point of view:

"At my parental home, after the death of my father, my mother decided the marriages of my brother and sister on the basis of exchange. She consulted my brothers, but did not ask me about my consent while arranging my marriage....My mother-in-law enjoys more decision-making power along with her elder son. My father-in-law also decides but, most of the time, matters are finalized by my mother-in-law."

Karim, a 35-year old man explains:

"My parents arranged my marriage when I was 20 years old. My parents kept in mind the level of education, age, the employment of myself and my spouse....A family does not think badly about their children and they have kept in mind the choice for them.... My wife and I did not see each other before the sohag raat (first night of marriage) because we were distant cousins and lived far away from each other....However, we were happy 
when we saw each other and we were happy about the choices made by our parents."

Khalid, a 35-year old man claimed that a parent's decision is in the favour of both spouses. He tells:

"It was a good rishta (spouse) because, on the one hand, my father-in-law's family was a religious one, which I liked. On the other hand, my wife herself was quite a reasonable spouse for me....My wife and I are comfortable with each other. We like each other."

Family choices regarding the selection of a mate are considered ideal and family has the responsibility of arranging the marriages of their son/ daughter. After the birth of a child, parents start to search the possible and potential spouse for their offspring. The mother starts thinking about the dowry of the daughter and the spouse for her. The father thinks about earning enough money for the dowry and the education of his children. However, girls, who have no facility of schools, help their mother in household chores. They assist their mothers in everyday household tasks such as cooking, washing and sewing. This dependency of an individual on the family is a dominant pattern that was found in the studied locality. It is evident not only from the daily affairs of the people, but is also visible in the selection of mates under the system of the exchange marriage.

\section{The Dynamics of the Husband-Wife Relationship: Priority for the Siblings}

Residents of the studied community considered that the responsibility of a husband is to fulfil the economic needs of his family, including his parents and the kin (especially brothers and sisters) who cannot earn a livelihood. A wife's responsibility is to manage the household affairs of the family. This includes cooking, chopping, mopping and washing the clothing for the family. Women also commonly work and assist men in the cultivation and harvesting of their land in the village. Nevertheless, a husband and wife are dependent upon each other in various other ways in the system of the exchange. A wife holds power in relation to controlling the behaviour of her husband due to the exchange mechanism. She enjoys a reciprocal relationship with her husband. In the case of a husband who does not take care of his wife, his exchanged sister will get the same response from her husband. In such a difficulty, a man's sister remains to be the priority for the man, even more so than his wife. This is contradictory to the Western marriage system, where a person disconnects from his/her family of origin and remains loyal to his/her marriage partner. Nevertheless, a husband and wife are seen as having a structural dependency on both partners, but the priority lies with the sibling. 


\section{Vulnerability (bride and in-law family relationships): Weak Individuals and Reciprocity}

In the early days of the exchange marriage, the bride perceives she is vulnerable to being adjusted in the family of procreation and is totally dependent on a number of relatives of the family-in-law. She is supposed to be careful and passive while settling in with the family of orientation, i.e. the in-laws. In the beginning, she is carefully watched and even a small 'mistake' made by the bride can create a problem. This problem can lead to a "cold war" in relations among the family members (Versa-Sanso, 1999). This trouble may even reach the exchanged couple. Therefore, the bride has to take care of a number of people at one time in a brand new home setting. She is treated as 'ideal' if she takes care of her relatives properly according to the "rules of the game".

However, normative rules for the groom are different. Usually he is neither relaxed from the strict observatory norm nor does he experience much vulnerability. He cares for his relatives but he also enjoys the reciprocal relationship more as compared to the bride. While explaining the asymmetrical and differential cultural expectations of the bride and bridegroom, one woman, aged 45 , tells that "a bride can only express this relationship as that she is 'exchanged', but she cannot force her husband to reciprocate with her parents".

The status of bride is not strengthened in a new family-in-law situation until the birth of a first or second child (preferably a boy) takes place. After that, a woman attains the level of maturity in accordance to the local norms and then she becomes the 'custodian of the house'. A man begins extending his authority with his marriage and becomes independent after the death of his father (in 'ideal' terms), but it depends on the given social conditions. At the stage of being grandparents, both the man and woman enjoy almost equal authority in household affairs, if they have still control on the economic resources. In the case where the grandparents are unable to control the economic resources, they become vulnerable and dependent upon their children. In such a situation, they may still enjoy the obedience of their children, but some children deny and ignore their elders. Children and youngsters are expected to be shy in front of their elders.

\section{Obedience to the Wife (run-mureed): Dominance and the Emphasis on Masculinity}

Men are socialized to be authoritative, rough and masculine. A typical husband is considered to be dominant over his wife. Conversely, if a wife is dominant, it is considered as a 'weaknesses' of the husband. Culturally, to be subservient to one's wife (in local language called run-mureed) is a negative and stigmatized character on the part of a husband. Such a man would be the laughing stock of the community and, therefore, the family of the "subservient husband" may exert pressure on him to behave "in a manly and proper manner." It is difficult for a man to resist such pressure. 
In times of trouble with one exchanged couple, the second exchanged couple has to reciprocate equally as per the normative rules. However, if the second exchanged couple does not want to reciprocate as per the rule of the game, then the man of the second couple is declared as a "run-mureed". He is declared to be unmasculine, weak and subservient to his wife. A 38-year old, male respondent, Rahim, said that he is not a runmureed and he does everything according to his own wish and does not like to consult with or inquire regarding the wish of his wife. He remains loyal to his family of procreation rather than the family of orientation in order to avoid the notion of being labelled as a run-mureed. According to him, it is against the local culture to be obedient to one's wife.

However, some people may privately be run-mureeds but, publicly, are "dominant husbands". Contrarily, Khalid, a 30-year old man, tells that he was labelled as a runmureed, but he did not care about these notions and, instead, focused on his conjugal affairs. Consequently, according to him, he has a happy marital life. He maintains a reciprocal relationship with his wife.

Obedience is considered to be a negative stance for a man to take and a positive symbol for a woman, which indicates the gender imbalance in this cultural context. Masculinity is the dominant value in the community that was studied. If a person resists this notion, he is perceived as a weak individual. Structural agents (family and kin) pressurize the man and try to make him conform to the normative roles in order to preserve the overall norms of masculinity.

\section{Dependence on a Wife's Earnings (run di kamai or nikhato): Social Pressure}

Men are supposed to earn money. It is their sole responsibility while women stay at home and manage the household. Hence, gender-specific earning is a dominant trait. An earning woman is considered to be a kamao aurat (earning woman) while an earning man is said to be a kamo-murd/ putar (earning man). In the studied community, it is an insult for a man if his wife is earning and the man is dependent upon her. Depending on one's wife's monetary earnings is a matter of shame and humiliation for a husband. In the marriage-exchange system, the dependency on a wife's earning brings further problems to the second exchanged couple.

It may be noted that it is not just a gender-specific division of labour or may not be a matter of personal choice, but it is a will of the society. For example, if a man depends on his wife's income, it is matter of serious concern to his parents. The family does not prefer that a woman should earn. A male respondent told us that he avoided becoming stigmatized due to relying on his wife's earnings as people label such a man as a nikhato (a lazy person). 
In the very process of socialization, both men and women are made conscious regarding their traditional roles. Accordingly, the wife expects and prefers to live at home, care for the children and do other home-related tasks. To accomplish such duties, she knows that she may not need much formal education. Therefore, while not sending daughters to high school, parents usually reason that "we do not except earnings from our daughters". In essence, the engagement of paid employment on the part of a daughter and later as a wife is considered a humiliation and dishonour for the family's prestige. A woman is comfortable being dependent upon her family and is accustomed to these norms. A female respondent tells that this dependency of a woman on her family makes her relax and she is then happy with her traditional role as a wife. In the marriage-exchange system, the second family compels the man who is not earning to get employment or to do some work/business in order to provide proper food and household items for the exchanged lady. He receives social pressure or even some kind of abuse (in local terms "taanay") to force him to reciprocate adequately. A person must earn in order to save his honour.

\section{Family Honour: Symbolic Culture}

A woman is the symbol of the cultural and family honour (Hussain, 2005). This honour must remain within the family in the case of marriage. Honour is further protected if it is reciprocal as in the exchange-marriage system. Girls are taught to take care of their parents' honour and family's prestige. They are trained to adopt a particular behaviour so that if they do marry on the basis of love, then they are responsible for spoiling their parents' prestige and honour. If someone wants to marry on the basis of love, then she has to do a court-marriage. After the court-marriage, she has to face sanctions from her family ${ }^{4}$. Finally, girls keep quiet because of parents' honour. These differences start from birth and continue throughout their life, even until death. Such differences are more significant for a woman to adopt than a man.

After marriage, a woman has to adjust in the new family set up. There may be a lot of differences between her parental and in-law homes, but the bride has to adjust there. Kalsoom, a 28-year old woman explained that her cousin, to whom she was engaged, wears traditional dress dhoti (name of the local dress) and she does not like him. This respondent claimed that her expected fiancé (who is also a cousin of the respondent), expects them to adopt their traditional way of life which makes her sceptical about being his wife and so she prefers not to marry him. However, it is difficult for her to decline this intended arrangement and she has to be the wife of that person, irrespective of her personal choice. In the case of refusal on her part, she will be subjected to punishment on the basis of honour. Therefore, she has to adjust herself in such a situation, but a male may escape from such a norm. Since her father already declared her exchange marriage, her deviancy is perceived as a violation of family honour. Such gender roles are stricter for a woman because she is perceived as a symbol of family honour and respect more so 
than a man. Caring for one's own family is a symbol of honour and is the prime aim of the life of the individual in rural Pakistan.

\section{Socialization and Reciprocity: Social Construction of the Reality}

Children are trained in a way that they develop their 'social frame' and 'social construction of the reality' and they design their 'world view' (Berger \& Luckmann, 1966; Berger, 1967). Children utilize the world view which they gain from their family and the prevailing social environment. In the village of Kabirwala, the people only have their own local world view: they learn from their family and cousins about their social values. They do not consider any alternative values as suitable substitutes for them.

From birth, there is a difference in the practices of socialization that take place for boys as compared to those for girls. A woman looks after a man's support from birth until death. A woman with the status of mother, daughter, sister and wife is honourable. According to a female respondent, "without these relations, she is nothing but a woman, which has question of worth and prestige". Children are believed to be the property of the elders and the extended family. They are taken care of in such a way that they likewise respond when the elders need their help. There is evidence of some discrimination regarding girls' education in a few places by thinking that they have to remain inside the home and, therefore, a little bit of education is enough for the girls ${ }^{5}$. Therefore, there is a wide gap in behaviour between spouses that shapes different world views. A person's social construction of reality is formulated within the given social and cultural conditions. This social construction of reality is based on the everyday experiences of the people. Individuals reproduce their social reality within the existing social frame.

\section{A Slight Change in the Spouse-Selection System: Obscured Emancipation of the Individual's Role}

An individual's emancipated or different role is traditionally resisted, even in personal affairs such as marital choice, but now it is changing slightly. Traditionally, an individual's identity is associated with family and kin. In ancient periods, a woman and children were considered as subordinate and dependent on a man (Urlin, 1969). Even nowadays in traditional communities, a woman and a man have to rely on their family. The individual's empowerment has always been the notion held by the modernist and feminist activists and is one that has affected everyday life in the West and other developing countries around the globe. It empowered the individual, especially women and has brought them into the mainstream of the society.

However, traditional societies (like Pakistan) are still struggling for this kind of social change. For instance, a son/daughter and a woman are all vulnerable in the village of Kabirwala. They have begun to argue about the traditional gender roles. We found two 
case histories where the spouses challenged the traditions and they violated the norms of the exchange marriage and they arranged their own marriages on the basis of love. One couple received severe, serious physical punishment from their respective families. The bride got more severe punishment than the groom and the couple had to divorce each other in order to marry their cousins on the basis of exchange. The other couple had even more serious consequences where the bride was killed while the groom managed to escape. Both of the couples were punished due to the 'violation' of the norms and the marriage-by-exchange system that had been pre-determined since their childhood. According to the local tradition of the exchange marriage, if a woman has not been exchanged with another woman, she suffers a lower social status.

Nonetheless, we also found some level of obscure transformation in the marriageexchange system. We found three couples who have their own marriage exchange, but they argued that they will not exchange their children, in order to avoid troubles. One couple declared that they "will not exchange" their children, but they will "arrange" their marriages among cousins. The second couple informed that they will not only decline the exchange but arrange their children's marriages by choice beyond cousins. The third couple, who was educated, seemed totally convinced about the love-marriage arrangement for their children without parents' consultation and they want to completely get rid of this "outdated tradition".

There are two approaches regarding this marriage-by-exchange system. (1) A woman enjoys a complete status because of the deterrence that is the balancing force in terms of the system in the studied locale. This 'deterrent' regulates both families who exchanged two women for their sons' marriages and therefore empowers these exchanged women. It is for the women's protection according to the local interpretations. Perceptions of the prevailing gender insecurity are common and a woman has a feeling of security from this exchange system (Jacoby \& Mansuri, 2006).

(2) According to a second opinion, it is an "outdated tradition". Some young respondents oppose the woman-exchange system. They claim that such a tradition is inhuman. A few elders also argue that the indigenous thinking of the women possesses outdated value. They claimed that the exchange system does not empower an individual. In this view, an individual must be free from the traditional role and responsibilities. The actors of the second approach (young generation) are challenging the tradition of exchange marriage which creates tension and conflict within the family. Owing to these problems and possibly to avoid such tension, the elders have started to garner the consent of the prospective, young couples, especially from the male who, by nature, is much more of a trouble-maker than a female. Such a situation leads to addressing the concerns of the young generation and trying to adjust to their modified or negotiated roles. For instance, now the families are arranging the marriages of their son/daughter on the basis of mutual consent of the couples but such arranged marriages are still limited to the cousins. Such a 
change is restricted to some educated and economically- independent persons. Furthermore, this option is more open for a man than for a woman.

\section{Changes in Education, Employment and Marriage: Obscured Transformation in the Gender Roles}

A slight, but steady transformation in marriage and gender roles is coming into the remote, rural community of Kabirwala. There is an emerging trend of considering the personal choice of the actors, contrary to the traditional system, among a few families. We found an educated family who supported their children (both a son and a daughter) not only to get higher education, but also to marry a cousin of their choice without exchange. They also allowed their daughter to teach at a local girl's school.

Similarly, some 'love marriages' were being celebrated by some families (but limited to cousins) because the children did take serious action. They tried to convince their elders as was reported by one respondent. Some spouses imagined that they will not impose their choice on their own children to arrange their marriages on the basis of exchange to avoid possible future tension in the family. A woman respondent narrates: "My husband thinks that if any proposal for his children seems fit to him, he will not object. He will marry his children without any type of family interception". Love-arranged marriage is the emerging trend among some of the community members although it is scarce and strictly controlled. This indicates a transition and new ideas in exploring the possibilities regarding marital relationships.

The community of Kabirwala is reshaping itself by taking some trends and attributes of modernization from other societies, for example 'love marriage' and reshaping itself according to the indigenous culture. This is the transitional phase from traditional to emerging global trends: changes in the values are visible that are interpreted according to the local values. For example, respondents try to link their actions within the customs. Despite the fact that their arguments may lack real theory related to culture or tradition, people maintain a rationality of their actions within the normative structure. According to a respondent "a boy and girl are the 'real actors' who perform the play (marriage) on the stage. Elders are the directors, while family/friends are supportive in understanding the real essence of the play and are the ones who influence the performance of the actors." The conjugal relationship depends upon these modified roles.

Education, awareness and employment opportunities can bring this tradition of the exchange marriage to an end. Both male and female respondents defended the stance that children's education leads towards an independent role for an individual. Education empowers a person and leads him/her to play an independent role as an individual. The trend to permit girls to acquire an education is increasing in the village of Kabirwala. 
According to Kalsoom, a female respondent, girls are now permitted to get higher education in college and university in limited cases. In the past era, girls were permitted to study but they could not pursue higher education. Now the trend is changing. They are permitted to get more education and even if they want to do a job, they can do so. However, on the contrary, girls are still not allowed to get married according to their own choice. This trend is increasing with the passage of time.

However, Aslam, a male respondent, does not agree with Kalsoom. He argued that it is common thought that girls have permission to study up to the matriculation level (ten years of schooling) or even until the completion of secondary-school (twelve years of education) but, in this case, they have to seek guidance within the village. According to him, co-education is not permissible in the village, but still they are encouraged to get education. In order to secure their reputations, girls do not go to university as the thought is that co-education harms their character and will affect the family's quality of repute. Meanwhile, separate universities for women have paved the way for females to pursue higher education if they are not interested in the co-education that exists in general universities.

This field work does not reflect a representation of a large segment of Pakistani society as it is limited to just some villages of Pakistan. Nonetheless, to some extent, it reflects the now-broader value system of the rural society. There are emotional, social and political forces attached that are helping the individual to adopt the 'situation-specific behaviour' which is close to the Hildenbrand (2007) concept of 'conditional matrix 6 , .

Nonetheless, social relationships between men and women are always under debate among the gender/feminist theorists. Gender roles and relationships have variations. In the West, a man and a woman have little dependence on their families. A man and a woman might have an equal level of autonomy (Becker 1974, 1991; Goody 2000; Sabean, Teuscher and Matheiu, 2007). In the East, a man and a woman have different roles and relationships, but they enjoy a limited degree of independent roles (Das 1973, 1976; Homa 1997). Our findings differ significantly from those of previous studies of the exchange marriage. We identified segregated gender roles and relations which are based on seniority and traditional authority. However, a woman is more inclined towards the exchange marriage than a man due to its "gender-specific structural roles" and the "rules of the game". A woman feels comfortable while following the traditions. However, at some point, the younger generation is ambivalent about the tradition of the exchangemarriage system and some of the young people remain reluctant to follow such traditions. Previous studies on the subject neglect the younger generations' opinion on the subject; they were taken for granted like an object. However, in this study, they were considered along with the "rules of the game". 


\section{A Theoretical Approach: The Interplay between Structure and Agency}

We interpret the system of the exchange marriage and gender roles within the context of the interplay between structure and agency. According to Giddens (1984), there is ongoing interplay between structure and agency which is reciprocal. Structure is produced and reproduced in an on-going interaction between the actors (Giddens, 1984). For Giddens, the actors are constantly and actively involved in the reproduction of the society. He labelled it "dualism of structure and agency". An actor produces social rules by his/her activities and then acts according to such rules. Social rules are "generalisable procedures, implemented in enactment or reproduction of social practices" (Giddens, 1984:21). From these social rules, a number of them are formal, clear, and codified and others are informal social rules (Giddens, 1984). Such social rules enable a person to have smooth relations with the society. He argues that the rules of the social order may only be latent but they are manifested when social expectations are not fulfilled and a reaction emerges from others. According to Giddens, a society provides the resources that facilitate an actor to learn a sense of 'social rules'. Giddens reveals that the authoritative resources (status and authority) establish command over other people (1984).

Differing from Giddens, Swell (1992) defines structure as based on fundamental constructs. He explains that the theory of structure accounts for agency, allows for change and bridges the gap between the semiotic and materialistic description of the structure. He explains the rule of symbols within the structure.

Meanwhile, Archer (1996) is critical of Giddens and she proposes that structure and agency are independent entities because both sides of the interplay can be analysed. She examines the independent domains of structure and agency and their relationship. Furthermore, she discusses the relative autonomy of culture from structure and agency. For her, the process by which complex transactions lead not only to changes in the structure of the system but also to an end product-structural elaboration which she calls "morphogenesis" (Archer, 1996: xxiv). She discusses the structural conditions and their effects on social interaction and how this interaction, in turn, leads to structural elaboration. She revealed that the relationship between culture, structure and agency has been neglected. She believes that the individual agency has the ability to either support or resist the pressure of the cultural system.

However, Dépelteau (2008) is critical of the co-determinism of Giddens and Archer. He criticizes the co-deterministic theories of structure and agency. He discusses the modern presuppositions: freedom, individualism and the search for a new social order (Dépelteau, 2008). He criticizes the notion of co-deterministic (structure $\leftrightarrow$ agency).

Dépelteau, (2008:51) proposes a relational approach (actor $\longleftrightarrow$ actor $\Longrightarrow$ structure). 
Regarding the issue of the exchange marriage and gender roles, relations can be analysed with this theoretical perspective. The gender relations, starting from the birth family, in hierarchical orders and circles around the family and the biradari (clan) are predominant in the village of Kabirwala. This order is shaped in patriarchal power and patronage in the village life of the Pakistani society (Lyon 2004 and Lindholm, 1982). The family controls the relationships for the whole life of an actor in the sub-continent (Jejeebhoy \& Sathar, 2001). An individual is subjected to adopting to the family and the biradari. A girl/boy, totally dependent on the family and the family-in-law, to becoming an independent person and then transforming to become the sole authority in later age is that which gives coercive authority in the villages of Pakistan.

\section{Conclusions}

The structure requires the conformity of the actor. However, the actor resists and demands for freedom, personal choice, emancipated roles and relationships. Structural forces (family, kin) compel a person to accept the standard social values. The actor either resists them or follows them. The interplay between structure and agency is dependent on certain prevailing social conditions. There is an on-going contradiction between the structural forces and an individual agency. Structural forces emphasize the maintenance of the "rules of the game", but an individual may resist, delay or deviate and want to maintain his/her emancipation and personal choice. Social forces of the structure (the family members and kin in our study) are responsible for maintaining the structure. The social conditions determine the nature of interaction between the structure and individual agency. This kind of interplay between social structure and agency brings social change. The change is negotiated, mediated and, in some social situations, is a controlled phenomenon in the social world.

\section{End Notes}

1. Pseudonym of the village is given to protect the privacy of the respondents.

2. This finding is similar to Bullock and Khalid's (1995) work.

3. Names of the respondents have been altered to protect the privacy of the respondents.

4. For more details, read a love- marriage story and notion of honour in Daily Jang online: http://www.jang.com.pk/jang/jul2009-daily/20-07-2009/update.htm\#13.

5. We found comparatively more educated men than woman in Kabirwala community. 
6. Conditional matrix defines that actor is subjected to adopt the situation specific behaviour and structural forces direct the actor to act accordingly.

\section{References}

Archer, M. S. (1996). Culture and agency: The place of Culture in Social Theory, Cambridge, Cambridge University Press.

Barman, Peter. (1997). Generalized Exchange, American Journal of Sociology, vol. 102(5) pp. 1383-1425.

Becker, Gary S. (1991). A Treatise on the Family, Cambridge, Harvard University Press.

Becker, Gary S. (1974). A Theory of Marriage, Part II, Journal of Political Economy 82 (2, part 2): S11-S26.

Berger, Peter \& Thomas, Luckmann (1966). The Social Construction of Reality: A Treatise in the Sociology of Knowledge, New York, Anchor Books.

Berger, Peter L. (1967). The Sacred Canopy: Elements of Sociology of Religion, New York, Anchor Books.

Boride, Pierre. (1998). Outline a Theory of Practice, Translated by Richard Nice, Cambridge, Cambridge University Press.

Bullock, Clive \& Fozia N. Khalid. (1995). Health Issues Related to Customary Consanguineous Marriage among British Pakistanis, Health Promotion International 10 (3), pp. 209-217.

Corbin, Juliet \& Anselm, Strauss (1990). Grounded Theory Research: Procedures, Canons and Evaluative Criteria, Zeitschrift für Soziologie 19 (6), pp. 418-427.

Das, Veena. (1973). Structure of Marriage Preferences: An Account from Pakistani Fiction, MAN 8 (1), pp. 30-45.

Das, Veena. (1976). Masks and Faces: An Essay on Punjabi Kinship, Contributions to Indian Sociology, 10 (1), pp. 1-30.

Dépelteau, François. (2008). Relational Thinking: A Critique of Co-Deterministic Theories of Structure and Agency, Sociological Theory, 26 (1), pp. 51-73. 
Giddens, Anthony. (1984). The Constitution of Society, Berkley, University of California Press.

Glaser, Barney G. (1992). Basics of Grounded Theory Analysis, Mill Valley, Sociology Press.

Glaser, Barney G. \& Anselm Strauss. (1965). Discovery of Substantive Theory: A Basic Strategy Underlying Qualitative Research, American Behavioural Scientist 8 (6), pp. 5-11.

Goody, Jack. (2000). The European Family, Oxford: Blackwell Publishers.

Heady, Patrick. (2001). Kinship, Courtship and Conscription: Levi- Straussian Aspects of Some Alpine Village Rituals, Halle, Max Planck Institute for Social Anthropology, Working Paper No.23.

Heady, Patrick. (2003). Conscripts and Christians: Reshaping Kinship and Affinity in the Carnian Alps, Journal of Royal Anthropological Institute, 9 (1), pp. 77-95.

Hildenbrand, Bruno. (2007). Mediating Structure and Interaction in The Sage Handbook of Grounded theory, Edited by A. Bryant \& K. Charmaz, Thousand Oaks, Sage Publications.

Homa, Hoodfar. (1997). Between Marriage and the Market Intimate Politics and Survival, California, University of California Press.

Hussain, Yasmin. (2005). Writing Diaspora: South Asian Women, Culture and Ethnicity, Burlington, Ashgate.

Jacoby, Hanan G. \& Ghazala, Mansuri (2008). Watta Satta: Bride Exchange and Women's Welfare in Rural Pakistan, Washington, DC, The World Bank.

Jejeebhoy, Shireen J. \& Zeba A, Sathar. (2001). Women's Autonomy in India and Pakistan: The Influence of Religion and Region, Population and Development Review, 27(4), pp. 687-712.

Larossa, Ralph. (2005). Grounded Theory Methods and Qualitative Family Research, Journal of Marriage and Family, 67, pp. 837-857.

Lindholm, Charles. (1982). Generosity and Jealousy: the Swat Pukhtun of Northern Pakistan, New York, Columbia. 
Levi-Strauss, Claude. (1969). The Elementary Structures of Kinship, Boston, Beacon Press.

Lyon, Stephen M. (2004). An Anthropological Analysis of local Politics and Patronage in a Pakistani village, London, Edwin Mellen Press.

Malinowski, B. (1961). Argonauts of the Western Pacific: An Account of Native Enterprise and Adventure in the Archipelagoes of Melanisian New Guinea, New York, Dutton.

Mauss, Marcel. (1954). The Gift. Glencoe, Free Press.

McDougal, Charles. (1979). The Kulunge Rai A Study in Kinship and Marriage Exchange, In Bibliotheca Himalayica Series iii, vol. IV, edited by H.K. Kuloy. Kathmandu: Ratna Pustak Bhandar.

Meek, C.K. (1936). Marriage by Exchange in Nigeria: A Disappearing Institution, Africa 9, pp. 64-74.

Neumann, W. Lawrence. (1997). Social Research Methods Quantitative and Qualitative Approaches, Needham Heights, Allyn and Bacon.

O'Brien, Marion. (2005). Studying Individual and Family Development: Linking Theory and Research, Journal of Marriage and Family, 67, pp. 880-890.

Qadeer, Mohammad Abdul. (2006). Pakistan Social and cultural transformation in a Muslim_nation, London, Routledge.

Sabean, David Warren, Simon, Teuscher, \& Jon, Matheiu (2007). Kinship in Europe: Approaches to Long- term Development (1300-1900). New York, Berghahn books.

Schweizer, Thomas \& Douglas R.White. (1998). Emergence, Development, and Transformation of Kin-based Exchange Systems, In Kinship, Networks and Exchange, edited by T. Schweitzer and D. R. White, Cambridge, Cambridge University Press.

Strathern, Marilyn. (1984). Marriage Exchanges: Melanesian Comment, Annual Review of Anthropology, 13, pp. 41-74. 
Strauss, Anselm L. (1987). Qualitative Analysis for Social Scientists, Cambridge, Cambridge University Press.

Strauss, Claudia and Naomi Quinn. (1997). A Cognitive Theory of Cultural Meaning, Cambridge, CUP.

Swell Jr., William H. (1992). A Theory of Structure: Duality, Agency and Transformation, The American Journal of Sociology, 98 (1), pp. 1-29.

Tapper, Richard. (1989). Ethnic Identities and Social Categories in Iran and Afghanistan, In History and Ethnicity, edited by M. Chapman, M. McDonald \& E. Tonkin, London, Routledge.

Tapper, Nancy. (1991). Bartered Brides: Politics Gender and Marriages in an Afghanistan Tribal Society, Cambridge, Cambridge University Press.

Urlin, Ethel L. (1969). A Short History of Marriages, Detroit, Singing Tree Press.

Versa-Sanso, Penny. (1999). Dominant Daughters-in-law and Submissive Mother-in- law? Cooperation and Conflict in South India, MAN 5 (4) 577- 93.

White, R. Douglas, \& Thomas Schweizr. (1998). Kinship, Property Transmission in Javanese Villages, In Kinship, Networks and Exchange, edited by T. Schweitzer and D. R.White, Cambridge, Cambridge University Press.

Zaman, Muhammad (2011). Methodological Gravitism. The Qualitative Report, vol. 16(6), pp. 1574-1598.

Dr. Muhammad Zaman is Assistant Professor in the Department of Sociology, Qauid-iAzam University.

Prof. Dr. Muhammad Zakria Zakar is Dean of Social Sciences, Director Institute of Social and Cultural Studies, University of Punjab.

Abida Sharif is Ph.D. Scholar at the University of Versailles, France. 